\title{
Mostrar e narrar: notas sobre o diálogo palavra- imagem nas ilustrações de Maurice Sendak
}

João Victor de Sousa Cavalcante, Instituto de Cultura e Arte, Universidade Federal do Ceará, Fortaleza, CE; E-mail: $<$ joaosc88@gmail.com>.

\begin{abstract}
Resumo
0 artigo discute as relações entre palavra e imagem na obra do ilustrador Maurice Sendak (1928-2012), notadamente o livro Where the Wild Things Are, de modo a compreender como o diálogo traçado entre as linguagens verbal e icônica compõe a diegese na literatura ilustrada. Historicamente, a relação entre palavra e imagem é caracterizada por querelas políticas, marcadas por alternâncias de poder e de modelos de representação. Com as transformações culturais do século XX, essas relações são redimensionadas e o livro ilustrado se apresenta como uma proposta que comunga as múltiplas potências desse encontro. Nosso objetivo é pensar como a circularidade das imagens e a linearidade do texto escrito convergem para uma harmonia estética nos livros de Sendak, nos quais imagens e palavras se traduzem de modo intersemiótico e compõem uma linguagem de intenso fluxo sígnico. Compreendemos a ilustração como um modelo de resistência da visualidade que evidencia a materialidade da obra, por meio da qual as imagens sobrevivem na interseção entre as artes visuais e a literatura. Ancoramos nossas discussões nos estudos sobre cultura visual, notadamente os trabalhos de Hans Belting, Georges Didi-Huberman e Vilém Flusser, além de estudos relacionados ao livro ilustrado, sobretudo a obra de Perry Nodelman.
\end{abstract}

Palavras-chave: Palavra, Imagem, llustração, Literatura, Maurice Sendak.

O que chamamos comumente de livro ilustrado é algo cuja tipificação é difícil, sobretudo por conta da rica variedade de formatos que estes assumem. De modo geral, ilustração literária é aquela em que os signos visuais são criados a partir de um texto verbal, ou em consonância a ele, com o qual cria uma relação polissêmica, apesar de ser dotada de certa autonomia. Contudo, esse diálogo entre palavra e imagem, que concebemos como uma relação de trocas sígnicas, se mostra bastante plural e diverso e assume muitas formas, conforme 0 
projeto da obra em que se inserem. A evolução do livro ilustrado está intimamente relacionada como uma história cultural da leitura e com os procedimentos tecnológicos de reprodução de textos.

O livro infantil ilustrado é, primordialmente, um artefato cultural, produzido no seio de uma sociedade, com o qual nos relacionamos segundo determinadas regras sociais, e que carrega um discurso próprio, em proporções específicas de sua produção, difusão e consumo. Imagens e palavras aparecem página ilustrada de modo peculiar e diferente se comparados a outros sistemas de representação verbais ou visuais. Desse modo, a imagem na ilustração não deve ser tratada isoladamente, tal como ocorre com outras formas de arte visual e de artes plásticas.

A defesa deste aporte metodológico é reforçada pelos estudos do pesquisador norte americano Perry Noldelman (1988), que também afirma que a crítica da ilustração não pode ser separada de elementos literários, pois as imagens isoladas não contemplam a harmonia narrativa e estética do livro ilustrado. É apenas no todo que a informação do livro infantil atinge sua eficácia ficcional, de modo que a sequencialidade das imagens, ancoradas pelo texto verbal, é que comunga as informações ficcionais enunciadas no livro ilustrado.

Nodelman explica que, apesar de voltada para os leitores mais jovens, a literatura ilustrada possui uma grande sofisticação estética que demanda do jovem leitor habilidades de leitura verbal e visual: as palavras completam informações que as imagens deixam em aberta e vice-versa, criando assim uma relação semiótica formada por um duplo vínculo informacional e comunicativo. Para Nodelman "picture books that tell stories force viewers to search the pictures for information that might add too or change the meaning of the accompanyng texts" (Nodelman, 1988: 18). Essa complexidade da literatura ilustrada sustenta-se no paradoxo de que esta é produzida para um leitor-observador ingênuo, infantil e pouco capacitado 
(pouco alfabetizado) que ainda não domina os códigos de representação dominantes na sociedade.

A tensão entre palavra e imagem não é exclusiva da ilustração literária e remonta a princípios de representação desde os primórdios das culturas humanas. Desde as pinturas rupestres nas cavernas de Lascaux, o homem comunicava-se (culturalmente, religiosamente, magicamente) por meio de imagens. Não era raro encontrar, no cristianismo primitivo, representações de Jesus Cristo em forma de peixe ou como um pastor de ovelhas, ou ainda altares e locais de culto ornados com imagens de santos ou de anjos, além das máscaras mortuárias, que continham em si as representações da vida, da morte e do sagrado, um sagrado inefável que só poderia ser conhecido pelos homens pelo símbolo mediador: a imagem.

Hans Belting (2011), ao propor uma conceituação antropológica da imagem, retoma seu caráter sagrado, no qual estão contidas as ideias de verdade e de realidade. Para o autor, "nos conceitos de imagens sobrevivem conceitos de fé, e as práticas das imagens alguma vez começaram como práticas de fé" (Belting, 2011: 2). Em resposta à iconofilia, surge um pensamento textolatra e iconoclasta, de onde se inicia uma perseguição incansável às imagens. $O$ iconoclasmo, no ocidente, consolida-se nos séculos VIII e IX, no Império Bizantino ${ }^{1}$, quando as imagens sagradas serão destruídas compulsoriamente, sob o pretexto de enfrentar as ameaças do Islã.

${ }^{1}$ No século VIII, o imperador bizantino Constantino V decretou uma série de leis iconoclastas, que proibiam a criação de imagens tumulares e religiosas, orientados pelo preceito de que a natureza divina, dada sua essência inefável, não poderia ser representada por imagens humanas. Sobre o tema ver Manguel (2000). 
Percebemos uma sucessão de fatos históricos que alimentam um pensamento de perseguição às práticas do imaginário, como, por exemplo, a Escolástica medieval, com seu representante mais famoso, São Tomás de Aquino, que buscava conciliar o racionalismo aristotélico com as verdades da fé cristã. Gilbert Durand (2010) reitera que a herança da filosofia de Aristóteles (bem como a filosofia platônica) induziu a difusão de um pensamento que considera a imagem como "amante do erro e da falsidade".

A imagem pode se desenvolver dentro de uma descrição
infinita e uma contemplação inesgotável. Incapaz de
permanecer bloqueada no enunciado claro de um
silogismo, ela propõe uma realidade velada enquanto a
lógica aristotélica exige 'claridade e diferença (Durand,
2010: 10). Contudo, alerta Durand, o imaginário sempre ofereceu resistências, mesmo após o desenvolvimento da imprensa e da física newtoniana, que excluíram definitivamente a imagem dos processos intelectuais. Um desses movimentos apontados pelo autor é (contraditoriamente à resistência bizantina) a floração de um culto à imaginária sacra gótica, nos séculos XIII e XIV. Outro período apontado por Durand como de fértil produção imagética é o Barroco, gerado no século XVI. Contudo é com o século $X X$ que a intensa produção de imagens volta a colocar em questão as relações entre o verbal e o visual em diversas obras, como as adaptações cinematográficas e os videoclipes.

O filósofo tcheco Vilém Flusser (2010) nos oferece outro olhar para pensar as relações entre palavra e imagem. $O$ autor propõe uma reflexão fenomenológica, em termos de temporalidade, na qual a consciência histórica é problematizada a partir das diferentes formas e gestos por meio dos quais informamos os objetos. Devemos ressaltar que, para Flusser, "gesto" é qualquer movimento do corpo, ou de um instrumento a ele unido, que expressam uma intenção. Para ele, antes do desenvolvimento da escrita, as imagens estavam sob os cuidados dos magos e se relacionavam com uma ideia mágico-religiosa de tempo circular. 
O pensamento exclusivamente imagético era, em essência, mítico e cíclico, no qual a história não era problematizada como um tempo contínuo, mas sim orientada pelo eterno retorno. Como o desenvolvimento dos sinais gráficos e da escrita linear, surge a consciência do tempo histórico ${ }^{2}$. Para o filósofo, a fenomenologia do ato de escrever sugere, já de início, uma reflexão sobre o pensamento, organizando-o linearmente. "Somente quando se escrevem linhas é que se pode pensar logicamente, calcular, criticar, produzir conhecimento científico, filosofar" (Flusser, 2010: 27).

Os magos são substituídos pelos escribas, e a realidade passa a ser concebida reflexivamente na dimensão da consciência histórica. Flusser também evidencia uma proposição ética e coletiva do ato de escrever. Para ele, o ato de escrever só se completa quando alcança o outro, o leitor.

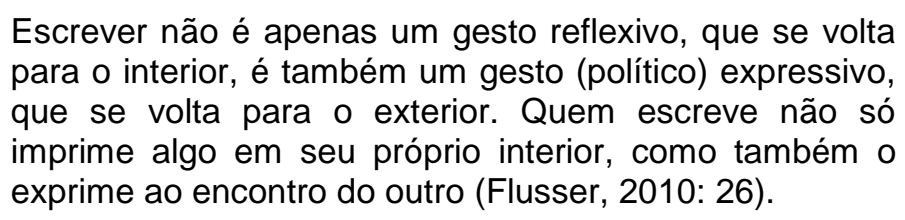

Roland Barthes (2007) trata literatura, escritura e texto como categorias equivalentes, como um "tecido de significantes" que constituem determinada obra. Barthes enumera três forças específicas que caracterizam o fato literário: a primeira (Mathesis) confere ao texto literário o caráter de realidade, independente da escola a qual este pertença; a segunda força (Mimesis) é a da representação, uma vez que o real não pode

\footnotetext{
2 Vilém Flusser divide a experiência histórica da humanidade em três estágios: a pré-história, anterior ao desenvolvimento da escrita e, portanto, desprovida de "consciência histórica"; a história, relacionada à ideia de reflexividade sobre os acontecimentos; e a pós-história, momento em que vivemos e que se relaciona com o futuro da escrita (Flusser, 2010). A experiência pós-histórica, marcada pelo elemento imagético, se realiza com o advento das imagens técnicas.
} 
ser representável em sua totalidade, a literatura se posiciona como uma tentativa de representação deste. A terceira força, Barthes denomina Semiosis:

Pode-se dizer que a terceira força da literatura, sua força propriamente semiótica, consiste em jogar com os signos em vez de destruí-los, em colocá-los numa maquinaria da linguagem cujos breques e travas de segurança arrebentaram, em suma, em instituir no próprio seio da linguagem servil uma verdadeira heteronímia de coisas (Barthes, 2007: 27-28).

É por meio desses jogos linguísticos que uma obra literária cria a realidade do personagem, trabalhando em cima dos recursos propostos pela língua, o que sugere, em certa medida, um recorte de linguagem preciso: a palavra e suas possibilidades finitas de codificação. A literatura, neste sentido, opera por sugestão, adjetivação, que cria para o leitor outro tipo de imagem mental, produzida sensualmente (Barthes, 2008). O escritor, portanto, dispõe de um arsenal limitado de palavras para definir os contornos de seu enredo e conferir-lhe verdade, dando a impressão de verossimilhança àquela ambientação.

Nossa intenção não é pensar imagem como superação da palavra, muito pelo contrário, reconhecemos que os dois modos de representação agem simultaneamente em diversos níveis de problematização, de tal modo que podemos pensar em imagens que são palavras (como os ideogramas chineses) ou palavras que são imagens (como a poesia concreta). $\mathrm{Na}$ literatura infantil ilustrada isso se evidencia de modo mais explícito, uma vez que texto e desenhos se comunicam em um processo de traduções sígnicas a ponto de formarem um texto único, não devendo ser lidos separadamente, e integrando a linearidade da palavra à abertura contemplativa da imagem.

Quando pensamos na obra de Maurice Sendak, percebemos esta relação. A questão da liberdade não é tão problematizada pelo fato de texto e imagem serem de um mesmo autor, contudo há um diálogo narrativo entre as duas formas, por um lado, o ele explora a potência sugestiva do texto literário, com suas adjetivações e convenções próprias da ficcionalidade. Por 
outro, nos traz outras informações por meio de imagens e das percepções sensórias que as texturas, cores e formas são capazes de produzir. Fica evidente na ilustração uma harmonia polifônica entre signos verbais e visuais de tal modo que, juntos, formam um único texto, acrescentando informações diferentes e complementares à narrativa.

Podemos observar estas relações com maior clareza na imagem abaixo. Na página dupla de Where the Wild Things Are, publicado em 1963, observamos o personagem Max ser coroado rei de todos os monstros. A leitura tem seu sentido preenchido na enunciação dos símbolos visuais por meio do texto, como por exemplo o uso da palavra "king" (rei) e a imagem de uma coração. Esta relação de ancoragem que o texto exerce sobre a ilustração serve nao apenas para reforçar o significado dos símbolos dispostos na página, como também para dinamizar a página, conferindo uma direção de leitura e ordenação dos acontecimentos da esquerda para direita.

Tal dinâmica dispõe os caracteres visuais em uma ordenação de acontecimentos quecompõem a diegese e os sentidos propostos pelo ato de leitura: os monstros em fila diante do rei, hierarquicamente dispostos em relação a Max; a profundidade da página indicando tempo e espaço; um sexto personagem na cena relutante atrás de uma árvore; a antropormofização dos monstros por meio da expressao facial e dos olhos. Estas informações só podem ser acessadas pela imersão na imagem e não constam no texto abaixo e nem podem ser "visualisadas" na narração oral desta história.

O texto verbal, contudo, não é mero acessório, ele entra na página, que passa a ser um todo visual orgânico e polifônico para dar estrutura e forma ao livro, e atua também como ponte com a proxima página, conferindo coesão e dependência entre as imagens, que passam pela leitura como quadros independentes. O sentido completa-se, portanto, na troca de informações, mas também na materialidade visual formada pelos caracteres verbais e icônicos, de modo que elementos 
diegéticos como tempo, espaço, foco narrativo etc., são criados por estas traduções contínuas entre palavra e imagem.

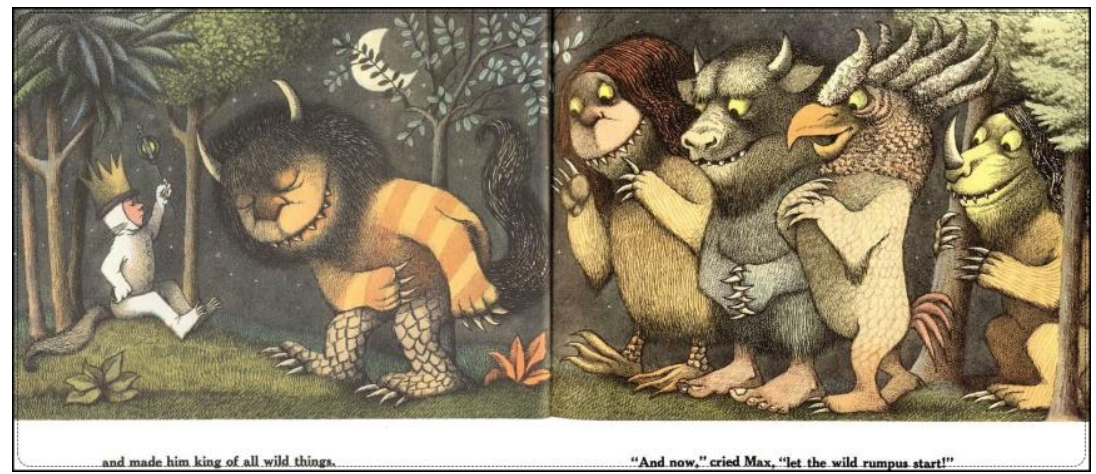

Fig. 1: Página dupla do livro Where the Wild Things Are (1963).

Encontramos no trabalho de Maria Nikolajeva e Carole Scott (2011) uma ampla discussão sobre o livro ilustrado, cuja variedade é resultado das numerosas relações entre palavra e imagem. As autoras propõem o conceito de iconotexto como uma fusão orgânica entre o que é escrito e o que é desenhado. Iconotexto seria, portanto, uma entidade indissociável composta por palavra e imagem que cooperam para elaborar e transmitir uma mensagem (Nikolajeva \&Scott, 2011). Aliado a isso, a materialidade da obra colabora para essa organicidade de linguagens, pois a própria página do livro e o modo como os elementos estão dispostos nela modifica a percepção da narrativa e seus elementos, tais como ponto de vista, foco narrativo etc.

A ilustração, portanto, sugere um olhar mais voltado para a contemplação de uma narrativa visual do que para uma racionalização lógica do que está sendo contado. Walter Benjamin (2012), em ensaio datado de 1928, ao explorar o universo dos livros infantis, afirma que este implica numa escrita simultânea entre obra e leitor, na qual a "criança redige dentro a imagem". Em detrimento disso "no reino das imagens incolores, a criança acorda; assim como, no reino das imagens coloridas, ela sonha seus sonhos até o fim" (Benjamin, 2012: 261). Desse modo, percebemos nas obras de Maurice Sendak uma estética polifônica que articula palavra e imagem de modo orgânico, onde observamos um fluxo contínuo de signos. 
Referências

Barthes, Roland. (2007). A Aula. São Paulo: Editora Cultrix.

(2008). O Prazer do Texto. São Paulo: Editora

Cultrix.

Belting, Hans. (2011). A Imagem Autêntica. São Paulo: Centro Interdisciplinar de Semiótica da Cultura.

Benjamin, Walter. (2012). Livros infantis antigos e esquecidos. In:_ Magia e técnica, Arte e Política. São Paulo: Editora Brasiliense.

Linden, Sophie Van der. (2011). Para Ler o Livro Ilustrado. São Paulo: Cosac Naify.

Horacio. (1997). Arte Poética. São Paulo: Cultrix.

Manguel, Alberto. (2001). Lendo Imagens. São Paulo: Companhia das Letras.

Nikolajeva, Maria e Scott, Carole. (2011) Livro Ilustrado: Palavra e Imagem. São Paulo: Cosac Naify.

Nodelman, Perry. (2012). Words About Pictures: the narrative art of children's picture books. University of Georgia Press: Athens.

Powers, Alan. (2011). Era uma vez uma capa: história ilustrada da literatura infantil. São Paulo: Cosac Naify, 2011. 